\title{
Climate reality - actual and expected
}

\author{
J. SALINGER \\ NIWA, P O Box 109 695, Newmarket, Auckland \\ j.salinger@niwa.co.nz
}

\begin{abstract}
New Zealand average surface temperatures have increased by $0.7^{\circ} \mathrm{C}$ since 1871 . In the last quarter of the $20^{\text {th }}$ century, more prevalent west to southwest flows occurred, accompanying a higher incidence of El Niño events. This resulted in annual rainfall decreasing in eastern areas of the North Island. As well as the global warming signal, interannual to decadal climate variability is a strong feature of east coast dryland climates. The El Niño-Southern Oscillation, (ENSO), through El Niño/ and La Niña episodes, drives climate variability seasonally. The recently described Interdecadal Pacific Oscillation (IPO) shifts climate every one to three decades and changes precipitation averages in these areas. These features of the climate system leave east coast dryland farming open to considerable climate variability.
\end{abstract}

Records of potential soil moisture deficit (PSMD) around Napier and Ashburton show that significant PSMD developed in these regions by 1 December, in 50 to $85 \%$ of years with severe deficits in 20 to $55 \%$ of years. These deficits build as summer progresses. El Niño events intensify, whilst La Niña episodes normally ameliorate these conditions on seasonal time scales. The IPO climate shifts significantly change the dryness of the soil of these areas, with the transition from negative to positive phases increasing PSMD by 35 to $50 \mathrm{~mm}$.

Climate change over the next few decades will be driven by the underlying trend of global warming. For New Zealand, this will be a warming of about 0.2 ${ }^{\circ} \mathrm{C}$ per decade. The latest scenarios and climate model results indicate that westerly circulation is likely to strengthen over New Zealand, with a drying of east coast climate in the order of $10 \%$ by 2080 . These will cause an increase in PSMD in the order of 20 to $30 \%$. ENSO and IPO variability will be a continuing feature of New Zealand climate in coming decades.

East coast dryland farms experience substantial climate variability. As climate warming continues in the decades of the $21^{\text {st }}$ century, these areas will become increasingly stressed as potential evapotranspiration (PET) rates increase, particularly when the IPO next changes phase and during E1 Niño events. Climate forecasting is an exciting new technology that will give farmers early warning and increase preparedness for dry seasons ahead, allowing them to make key strategic decisions. A mixture of new and traditional technologies will also assist, such as intercropping and use of seasonal climate forecasting. Despite this, dryland farming systems are likely to become increasingly limited owing to low rainfall and high potential evapotranspiration rates.

\section{Introduction}

In New Zealand dryland climates rainfall does not satisfy plant water demands, because there is not enough rain to meet the demand of potential evapotranspiration (PET). The deficit in rainfall can be quantified as the potential soil moisture deficit (PSMD) - the accumulated difference between PET and rainfall over the July to June growing season. PSMD levels that will not sustain plant growth develop once values are in excess of $100 \mathrm{~mm}$, with significant loss of pasture production when deficits are greater than $150 \mathrm{~mm}$ (McAneney et al. 1982; Porteous et al. 1994). In the dry eastern areas of New Zealand, PSMDs over the growth season typically accumulate to between 300 and $500 \mathrm{~mm}$, with values in the order of 100 to $150 \mathrm{~mm}$ by the beginning of December, and further deficits of 120 to $150 \mathrm{~mm}$ accumulating in January and February. The PSMD, because it is cumulative, is a measure of the intensity and duration of drought. The historical timing, frequency and duration of such events have important implications for management options for dryland pastures.

New Zealand average surface temperatures have increased by $0.7^{\circ} \mathrm{C}$ since 1871 (Folland et al. 2003). The warmest year on record was 1998 (Salinger et al. 2000). In the last quarter of the $20^{\text {th }}$ century more prevalent west to southwest flows occurred accompanying a higher incidence of El Niño events. This resulted in annual rainfall decreasing in eastern areas of the North Island. East coast dryland climates 
are also variable. The El Niño/Southern Oscillation (ENSO) drives actual climate variability on an interannual basis (Mullan 1995). The Interdecadal Pacific Oscillation (IPO), shifts climate every one to three decades (Mantua et al. 1997; Salinger \& Mullan 1999; Salinger et al. 2001; Salinger 2000a and 2000b). Climate change over the next few decades will be driven by the underlying trend of global warming. For New Zealand this translates to a warming of about $0.2{ }^{\circ} \mathrm{C}$ per decade (Wratt et al. 2003). However, interannual to decadal climate variability will operate in coming decades on this background trend.

As climate warming continues in the decades of the $21^{\text {st }}$ century, the dryland east will become increasing stressed as PET rates increase. This paper reviews the development of drought and PSMD from the historical record at two typical east coast dryland locations. The implications of ENSO (interannual) and IPO (decadal) variability underneath the background climate trends from global warming will be discussed together with climate forecasting as a new technology that will give farmers early warning and increase their preparedness for dry seasons ahead.

\section{Historical potential soil moisture deficit}

The PSMDs have been calculated for two typical east coast locations: Napier in Hawke's Bay and Ashburton Domain in Canterbury. The PSMDs have been calculated over the July to June growing season, where PET is the accumulated difference between PET and rainfall on a daily basis. These calculations were made for the period 1930 to 2002 (Figure 1a). The rainfall records were carefully screened for possible heterogeneities of the data by examining station histories (Fouhy et al. 1992) to identify site changes or other possible environmental changes near the climate station site. Statistical procedures (Rhoades \& Salinger 1993) were then used to homogenise the data.

Ashburton is typical of Canterbury dryland areas and had an average PSMD of $325 \mathrm{~mm}$ over the 71year period. This region's PSMD was over $500 \mathrm{~mm}$ in $1984 / 85$ and below $120 \mathrm{~mm}$ in 1950/51. Significant deficits will depend on the water holding capacity of soils, which varies depending on the soil type and depth. For the purposes of this study, $100 \mathrm{~mm}$ is used as a significant PSMD and $150 \mathrm{~mm}$ as a severe PSMD (McAneney et al. 1982). A significant PSMD of 100 mm or more from 1 July to 1 December occurs in about half of the years (Table 1) and for $70 \%$ of the years in January and February (Figure 1b). The frequency of severe PSMD is 18 and $33 \%$, respectively, for the earlier and later times of the year.

Napier is typical of the dryland conditions in the east of the North Island. In contrast with Ashburton, rainfall at Napier is higher (annual mean $830 \mathrm{~mm}$, c.f. with $750 \mathrm{~mm}$ at Ashburton), and higher PET rates, by about $140 \mathrm{~mm}$, leading to higher potential deficits (Figure 1a). Significant PSMDs occur in $85 \%$ of years to the period 1 December, and also in the 1 Jan -1 Mar period (Figure 1b). The frequency of severe PSMD also increases to a frequency of 55 and $52 \%$, respectively, for early and late periods. The Napier average PSMD for the July to June year of $444 \mathrm{~mm}$ is a result of higher mean annual temperatures and more solar radiation than in Canterbury. A consequence of this is that severe PSMD develops earlier in Hawke's Bay than in Canterbury, and its occurrence is also more frequent later in the season.

\section{Actual climate variability}

The strong variability of east coast dryland climates is associated with fluctuations in the prevailing westerlies and in the strength of the subtropical highpressure belt. There are two key natural cycles that operate over timescales of years (Southern Oscillation) and decades (IPO).

The ENSO is a tropical Pacific-wide oscillation that affects pressure, winds, sea-surface temperature (SST) and rainfall (Gordon 1986). In the El Niño phase, the easterly trade winds weaken, and SSTs in the eastern tropical Pacific can become several degrees warmer than normal. New Zealand experiences stronger than normal southwesterly airflow (Mullan 1995). This generally results in lower seasonal temperatures for New Zealand, and drier conditions in the northeast of the country. Conversely, La Niña events weaken the prevailing west to southwest airflow over New Zealand, allowing more moisture to be brought into these regions in easterly and northeasterly episodes. In contrast, dryland areas in Otago and South Canterbury receive less rain. Recently shifts in climate have been detected in the Pacific basin, driven by the IPO (Salinger \& Mullan 1999), which shifts climate every one to three decades. The two phases of the IPO bring either drier conditions, especially to eastern areas of the North Island, or wetter and warmer conditions.

To quantify the impacts of these features of natural variability, potential deficit years were partitioned into (a) El Niño and La Niña years and (b) IPO positive 
Table 1 Magnitude of potential soil moisture deficit (PSMD) (mm) at Ashburton and Napier from 1930-2002.

\begin{tabular}{|c|c|c|c|c|}
\hline \multirow[b]{2}{*}{ PSMD (mm) } & \multicolumn{2}{|c|}{ Ashburton } & \multicolumn{2}{|c|}{ Napier } \\
\hline & No. Years & $\%$ Years & No. Years & $\%$ Years \\
\hline $1 \mathrm{Jul}-1 \mathrm{Dec}>100$ & 36 & 51 & 60 & 85 \\
\hline $1 \mathrm{Jul}-1 \mathrm{Dec}>150$ & 13 & 18 & 39 & 55 \\
\hline 1 Jan -1 Mar $>100$ & 49 & 69 & 61 & 85 \\
\hline 1 Jan -1 Mar > 150 & 23 & 33 & 37 & 52 \\
\hline
\end{tabular}

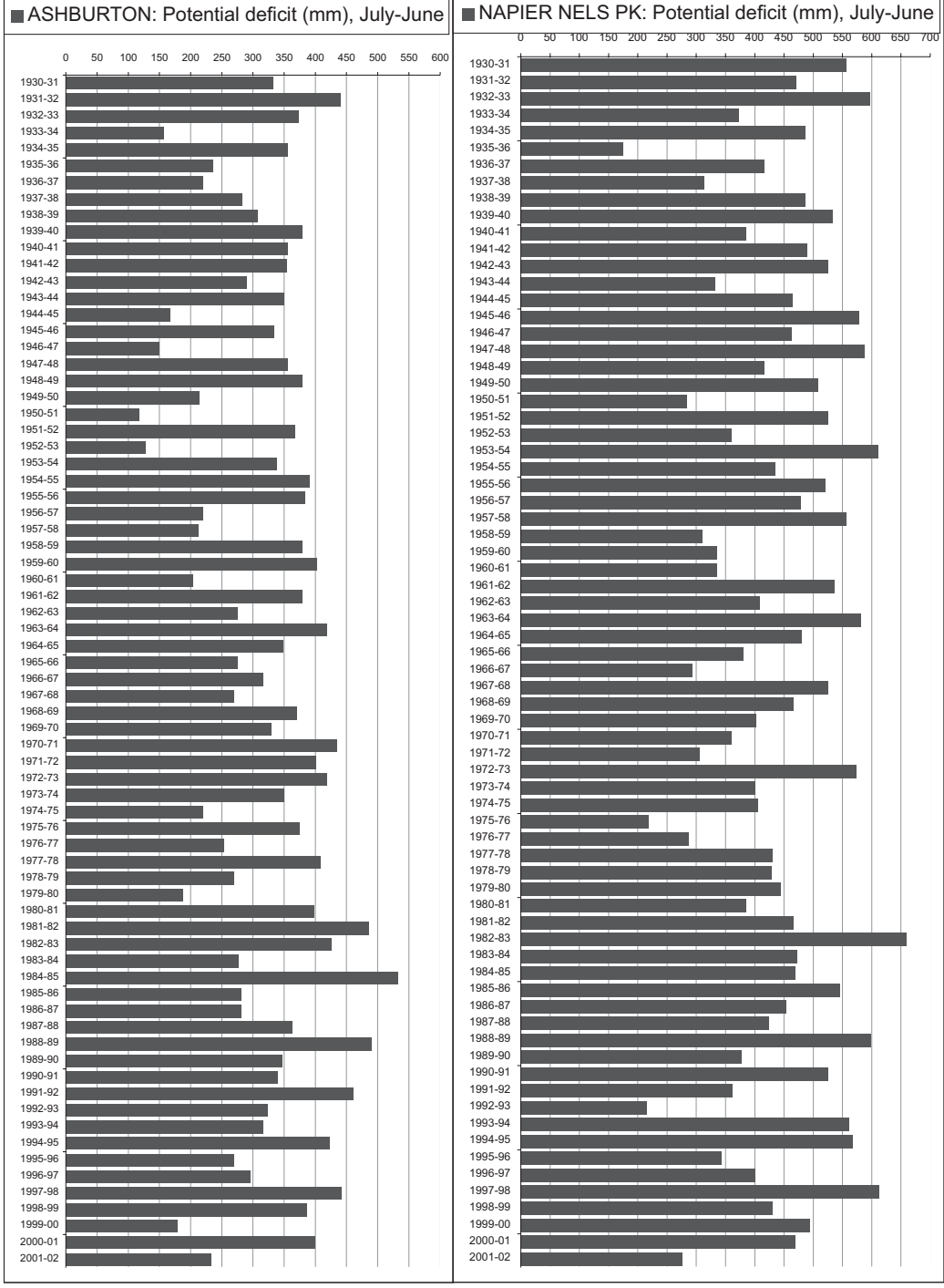

Figure 1a Potential soil moisture deficit (PSMD) in $\mathrm{mm}$ accumulated over the July-June growing season for Ashburton and Napier for the period 1930-2002. and IPO negative years. El Niño seasons were drier at both Ashburton, and especially Napier, in comparison with La Niña seasons (Table 2). Similarly, the IPO positive phase, decades when stronger westerlies prevail with more anticyclones over northern New Zealand, is associated with significantly higher PSMD values at these two sites compared with the wetter, more easterly negative phase.

\section{Expected climate change}

For New Zealand the effects of global warming translates to a warming of about $0.2{ }^{\circ} \mathrm{C}$ per decade. The latest scenarios and climate model results indicate that the westerly circulation is likely to strengthen over New Zealand, with a drying of east coast climate in the order of $10 \%$ by 2080 (Wratt et al. 2003). Changes in annual and seasonal temperature and precipitation for regional council areas (Table 3 ) have recently been published (Wratt et al. 2003).

These scenarios show clearly that the dryland areas of New Zealand will become warmer and drier, except in the western parts of Otago and Canterbury foothills. Midrange precipitation decreases are in the order of $15 \%$ in Gisborne and Hawke's Bay and 5 to $10 \%$, respectively, in Marlborough and eastern parts of Canterbury. The midrange temperature increase of $2{ }^{\circ} \mathrm{C}$ will increase PET rates in the 
order of $5 \%$. This will translate to an increase in PET of about $50 \mathrm{~mm}$ at Napier and $40 \mathrm{~mm}$ at Ashburton, with respective midrange decreases in annual rainfall by 125 and $55 \mathrm{~mm}$. Thus, climate warming will significantly increase PSMD at these two locations. The magnitude of change is in the order of $175 \mathrm{~mm}$ at Napier and $90 \mathrm{~mm}$ at Ashburton, implying earlier development of significant and severe PSMD in dryland east coast areas.

Climate variability will operate in coming decades on these background trends. The IPO very likely changed phase in or near 1998 (Salinger et al. 2003). This is expected to produce a warmer and wetter climate for many east coast dryland areas, but with lower precipitation in Otago and South Canterbury for the next two decades. On top of these decadal changes, ENSO will continue to increase the interannual variability that already occurs. Finally, other phenomena, such as volcanic eruptions, which inject aerosols into the stratosphere, produce significant climate perturbations sporadically.

\section{Discussion and conclusions}

Managing climate variability and change requires climateproofing activities that address increasing variability, extremes, shifts and changes from seasons to decades and longer-term change during the $21^{\text {st }}$ century. In particular, adaptation of dryland farming systems to increasing climate
Table 2 Impacts of annual and decadal variability on potential soil moisture deficit: Ashburton and Napier.

\begin{tabular}{lcc}
\hline & $\begin{array}{c}\text { Ashburton } \\
\text { PSMD (mm) }\end{array}$ & $\begin{array}{c}\text { Napier } \\
\text { PSMD }(\mathrm{mm})\end{array}$ \\
\hline El Niño & 367 & 494 \\
La Niña & 340 & 429 \\
IPO positive & 361 & 466 \\
IPO negative & 312 & 431 \\
\hline
\end{tabular}

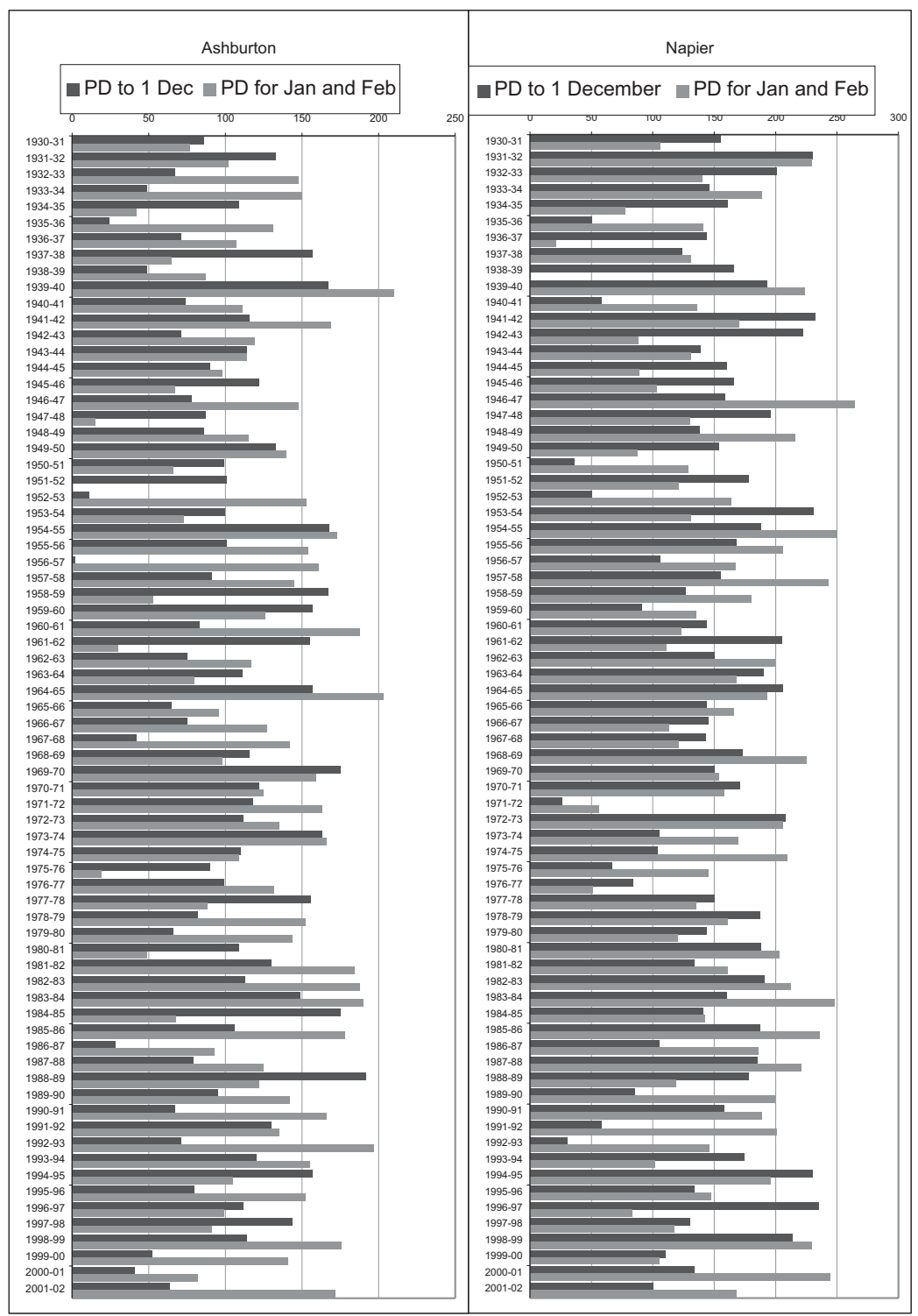

Figure 1b Potential soil moisture deficit (PSMD) in $\mathrm{mm}$ accumulated over the 1 July to 1 December (black) and 1 January to 1 March (grey) seasons for Ashburton and Napier for the period 1930-2002. 
Table 3 Range of predicted changes for each regional council area in seasonal and annual mean temperature (in ${ }^{\circ} \mathrm{C}$ ) and precipitation (in \%), for 1990 to 2070-2099 (the "2080s"), scaled to the full IPCC range of global warming (adapted from Wratt et al. 2003).

\begin{tabular}{|c|c|c|c|c|c|}
\hline \multicolumn{6}{|c|}{ Temperature $\left({ }^{\circ} \mathrm{C}\right)$} \\
\hline & Summer & Autumn & Winter & Spring & Annual \\
\hline Gisborne & 0.4 to 3.9 & 0.5 to 3.8 & 0.8 to 4.1 & 0.6 to 3.4 & 0.6 to 3.8 \\
\hline Hawke’s Bay & 0.3 to 3.9 & 0.5 to 3.8 & 0.8 to 4.0 & 0.5 to 3.3 & 0.5 to 3.8 \\
\hline Marlborough & -0.2 to 3.5 & 0.4 to 3.6 & 0.9 to 4.1 & 0.2 to 3.3 & 0.4 to 3.5 \\
\hline Canterbury & 0.0 to 3.3 & 0.4 to 3.5 & 0.8 to 3.9 & 0.3 to 3.1 & 0.5 to 3.4 \\
\hline Otago & -0.1 to 2.7 & 0.4 to 3.3 & 0.7 to 3.5 & 0.2 to 3.0 & 0.4 to 3.1 \\
\hline \multicolumn{6}{|c|}{ Precipitation (\%) } \\
\hline Gisborne & -22 to +19 & -56 to +13 & -38 to +24 & -72 to -4 & -35 to +4 \\
\hline Hawke's Bay & -31 to +26 & -54 to +11 & -43 to +25 & -59 to -1 & -37 to +5 \\
\hline Marlborough & -23 to +46 & -22 to +12 & -32 to +37 & -37 to +14 & -24 to +15 \\
\hline Canterbury & -28 to +51 & -44 to +36 & -70 to +93 & -47 to +34 & -41 to +42 \\
\hline Otago & -11 to +46 & -25 to +46 & -22 to +129 & -16 to +45 & -9 to +57 \\
\hline
\end{tabular}

variability and extremes will provide some protection to long-term change. Such strategies include improved paddock, grazing and livestock management and better water supply in paddocks.

Modern climate forecasting provides climate guidance for the next three months, with a lower level of trend guidance in climate to six months. El Niño seasons, compared to La Niña seasons, are consistently drier in the eastern dryland regions of New Zealand, by 25 to $50 \mathrm{~mm}$, with significant and severe PSMD developing earlier in the growing season. This seasonal climate forecasting can increase preparedness and lead to better social, economic and environmental outcomes for farmers and their communities. Such forecasting is one of many risk management tools that can play an important role in decision-making. To effectively manage risk, a participatory, cross-disciplinary research approach is needed that brings together institutions (partnerships), disciplines (such as climate science, agricultural systems science, rural sociology, etc.) and people (scientists, policymakers and direct beneficiaries) as equal partners to reap the benefits from climate forecasting. Climate science can provide insights into climatic processes, agricultural systems science can translate these insights into management options and rural sociology can help to determine the options that are most feasible or desirable from a socio-economic perspective.
The IPO climate shifts provide medium-term planning horizons that can be made for the decade commencing 2000. The recent shift to the negative phase of the IPO implies a wetter and warmer climate, especially in dryland areas of Gisborne and Hawke's Bay. This reduces PSMD deficits by 35 to $50 \mathrm{~mm}$. Such a reduction will be of benefit to dryland management systems. However, the predicted next IPO shift to the positive phase in the decade 2010 or 2020 will provide a challenge.

Climate models of $21^{\text {st }}$ century global warming coupled with climate scenarios provide sensitivity analysis tools for long-term planning. To implement these successfully requires close cooperation between research agencies and agribusiness. Dryland pastoral systems need to be resilient to wetter and drier seasons and decades. It is essential that emphasis be placed on long-term planning for the management of dryland systems with global warming. All projections indicate that a drying of climates in these areas will place more limitations on farming systems because of lower soil moisture levels. East coast climates will continue to vary as they warm with drying from Gisborne to North Canterbury, should the scenarios of future climate prove correct.

\section{ACKNOWLEDGEMENTS}

This research was supported by the New Zealand Foundation for Research, Science and Technology, 
contract no. C01X0202. Alan Porteous (NIWA) provided the PSMD data for Napier and Ashburton.

\section{REFERENCES}

Folland, C.K.; Salinger, M.J.; Jiang, N.; Rayner, N. 2003. Trends and variations in South Pacific island and ocean surface temperatures. Journal of Climate 16(17): 2859-2874.

Fouhy, E.; Coutts, L.; McGann, R.; Collen, B.; Salinger, J. 1992. South Pacific historical climate network. Climate station histories. Part 2: New Zealand and Offshore Islands. New Zealand Meteorological Service, Wellington. $216 \mathrm{pp}$.

Gordon, N.D. 1986. The Southern Oscillation: and New Zealand weather. Monthly Weather Review 114: 371-387.

McAneney, K.J.; Judd. M.J.; Weeda, W.C.; Hall, A.J. 1982. Loss in monthly pasture production resulting from dryland conditions in the Waikato. New Zealand Journal of Agricultural Research 25: 151156.

Mantua, N.J.; Hare, S.R.; Zhang, Y.; Wallace, J.M.; Francis, R.C. 1997. A Pacific interdecadal climate oscillation with impacts on salmon production. Bulletin of the American Meteorological Society 78: 1069-1079.

Mullan, A.B. 1995. On the linearity and stability of Southern Oscillation-climate relationships for New Zealand. International Journal of Climatology 15: 1365-1386.

Minstry for the Environment. 2003. Chapter 2: Projections of future New Zealand climate change. pp. 5-31. In: Overview of climate change effects and impacts assessment: A guidance note for local government in New Zealand. Wellington.

Porteous, A.S.; Basher, R.E.; Salinger, M.J. 1994. Calibration and performance of the single-layer soil water balance model for pasture sites. New Zealand Journal of
Agricultural Research 37: 107-118.

Rhoades, D.A.; Salinger, M.J. 1993. Adjustment of temperature and rainfall records for site changes. International Journal of Climatology 13: 899913.

Salinger, M.J. 2000a. The Genesis of a New Ark: Integrating preparedness for increasing climate variability and change. pp. 31-37. In: Managing the Impacts of Climatic Variability: The Noah Paradigm. Proceedings of the New Zealand Institute of Agricultural Science and the New Zealand Society for Horticultural Science Annual Convention 2000, Massey University, Palmerston North, 27-29 June 2000.

Salinger, M.J., 2000b. Chapter 6, Wet 'n Wild. Pp. 124154. In: Awesome Forces: Natural hazards that threaten New Zealand. Eds. Hicks, G.; Campbell , H. Te Papa Press, Wellington.

Salinger, M.J.; Gray, W.; Mullan, A.B; Wratt, D.S. 2003. Chapter 2, Atmospheric circulation and precipitation. In: Freshwaters of New Zealand. Eds. Mosley, P.; Sorrell, B.; Pearson, C.; Harding, J. Caxton Press, Christchurch (in press).

Salinger, M.J.; Jiang, N.; Folland, C.K. 2000. Observed temperature trends and variations in the New Zealand region, 1871-1998. In: Managing the Impacts of Climatic Variability: The Noah Paradigm. Proceedings of the New Zealand Institute of Agricultural Science and the New Zealand Society for Horticultural Science Annual Convention 2000, Massey University, Palmerston North, 27-29 June 2000.

Salinger, M.J.; Mullan, A.B. 1999. New Zealand climate: Temperature and precipitation variations and their links with atmospheric circulation 19301994. International Journal of Climatology 19: 1049-1071.

Salinger, M.J.; Renwick, J. A.; Mullan, A.B. 2001. Interdecadal Pacific Oscillation and South Pacific climate. International Journal of Climatology 21: 1705-1721.

Wratt, D.S.; Mullan, A.B.; Salinger, M.J; Allan, S.; Morgan, T.; Kenny, G. 2003. Overview of climate change effects and impacts assessment - A guidance manual for local government. Ministry for the Environment, Wellington (in press). 